OPEN ACCESS

Edited by:

Miao Qu,

Capital Medical University, China

Reviewed by:

Suqian Duan,

King's College London,

United Kingdom

Weijia Gao,

Zhejiang University, China

*Correspondence:

Bangshan Liu

bangshan.liu@csu.edu.cn

Lingjiang Li

Ilj2920@163.com

tThese authors have contributed equally to this work

Specialty section:

This article was submitted to Mood and Anxiety Disorders,

a section of the journal

Frontiers in Psychiatry

Received: 21 June 2021

Accepted: 16 September 2021

Published: 22 October 2021

Citation:

Jugessur R, Zhang Y, Qin X, Wang $M$, Lu X, Sun J, Dong Q, Zhang L, Liu J, Ju Y, Liao M, Wan P, Guo H, Zhao F,

Liu B and Li L (2021) Childhood Maltreatment Predicts Specific Types of Dysfunctional Attitudes in

Participants With and Without Depression.

Front. Psychiatry 12:728280 doi: 10.3389/fpsyt.2021.728280

\section{Childhood Maltreatment Predicts Specific Types of Dysfunctional Attitudes in Participants With and Without Depression}

Raj Jugessur ${ }^{1,2 \dagger}$, Yan Zhang ${ }^{1,2 \dagger}$, Xuemei Qin ${ }^{1,2}$, Mi Wang ${ }^{1,2}$, Xiaowen Lu $^{1,2}$, Jinrong Sun ${ }^{1,2,3}$, Qiangli Dong ${ }^{1,2}$, Liang Zhang ${ }^{1,2}$, Jin Liu ${ }^{1,2}$, Yumeng Ju ${ }^{1,2}$, Mei Liao ${ }^{1,2}$, Ping Wan ${ }^{4}$, Hua Guo ${ }^{4}$, Futao Zhao ${ }^{4}$, Bangshan Liu ${ }^{1,2 *}$ and Lingjiang $\mathrm{Li}^{1,2 *}$

${ }^{1}$ National Clinical Research Center for Mental Disorders, Department of Psychiatry, The Second Xiangya Hospital of Central South University, Changsha, China, ${ }^{2}$ Mental Health Institute of Central South University, China National Technology Institute on Mental Disorders, Hunan Technology Institute of Psychiatry, Hunan Key Laboratory of Psychiatry and Mental Health, Changsha, China, ${ }^{3}$ Affiliated WuTaiShan Hospital of Medical College of Yangzhou University, Yangzhou Mental Health Centre, Yangzhou, China, ${ }^{4}$ Zhumadian Psychiatric Hospital, Zhumadian, China

Background: Studies have shown a strong association between childhood maltreatment (CM) and major depressive disorder (MDD). Dysfunctional attitudes (DAs) play a crucial role in the development of MDD. In this study, we aimed to investigate whether (1) DAs are associated with CM, (2) specific CM types predict specific types of DAs, and (3) higher childhood trauma counts (CTCs) predict more DAs.

Methods: One hundred seventy-one MDD participants and 156 healthy controls (HCs) were enrolled for the study. CM was assessed retrospectively with the Childhood Trauma Questionnaire. DAs were evaluated using the Chinese version of the Dysfunctional Attitude Scale-Form A (C-DAS-A). A series of analyses, including multiple analyses of covariance and hierarchical regression analyses, were used in this study to examine the hypotheses.

Results: The proportion of CM was $60.2 \%$ in the MDD group and $44.2 \%$ in the HC group. The $2 \times 2$ analysis of covariance results showed no interaction effect between $\mathrm{CM}$ and MDD on C-DAS-A total score. When the factor scores replaced the C-DAS-A total score, a similar trend was observed. Within the MDD group, emotional abuse (EA) predicted two forms of DAs: self-determination type and overall DAs; physical neglect (PN) was predictive of attraction and repulsion-type DAs. Higher childhood trauma counts significantly predicted more types of DAs in the MDD group.

Conclusion: DAs are a trait feature of CM. EA and PN predict specific types of DAs in MDD patients. Higher CTCs predict more DAs in MDD patients.

Keywords: childhood maltreatment, dysfunctional attitudes, MDD, polyvictimization, depression 


\section{INTRODUCTION}

Childhood maltreatment (CM) is deviant behavior toward an underage that causes harm or entails a risk of causing harm in physical, sexual, and emotional aspect. Several CM forms are recognized: emotional abuse (EA), physical abuse (PA), sexual abuse (SA), and neglect [emotional neglect (EN) and physical neglect (PN)] (1). It constitutes a global threat leading to significant health concerns. Worldwide, one of two children is a victim of any form of CM (2). They lead to severe long-term consequences not limited to work and relationship difficulties, disappointing academic performance, and impaired mental health, including major depressive disorder (MDD) (3-5). Individuals who underwent CM exhibit psychological consequences and disruptions in neurobiological mechanisms; the stress system is affected, and there is impeded brain connectivity, primarily in the frontal brain cortex $(6,7)$.

Depression is one of the leading causes of psychiatric morbidity globally (8); documentation of its association with CM is not scarce in the medical literature $(9,10)$. Some reported that MDD was twice likely in individuals with CM (11). CM has a varying effect on depression onset (12), course and response to treatment, and other attributes $(10,13)$. When considering the individual types of CM, EA increases the risk of depression twice as likely as PA (14); others suggested EN significantly predicts depression, whereas EA correlates with depression severity (15). Under Beck's views of depression, a negative self-schema may be acquired during childhood due to scarring life events. Those are not limited to abuse and neglect. The negative self-schemas remain quiescent unless triggered by stressors (16). Those negative self-schemas, commonly referred to as dysfunctional attitudes (DAs), are ubiquitous negative thought processing styles that affect one's belief about oneself, the world, and the future; they are at the core of depressive pathologies. Several studies thoroughly investigated the impact of DAs in depression patients. They constitute a considerable risk and poorer prognosis of depression (10), as well as being a long-term predictor for relapse (17) and decreased effectiveness to antidepressant therapy (18). The relationship between CM and MDD is moderated by DAs $(19,20)$. However, not all individuals with DAs will develop depressive disorders, leading us to contemplate whether DAs are a trait resulting from CM. Also, as the individual types of $\mathrm{CM}$ have varying effects on depression, could it be possible for the specific CM types to forecast global DAs and specific DAs? Nevertheless, this relationship is unexplored. Only a few studies partly address the question. In a study involving a sample of women, the researcher suggests a significant association between EA and DAs (19). Another researcher suggests a significant association between childhood neglect (CN) and DAs (20). The amount of DAs influences the threshold of an adverse event to onset depression; the higher the DAs grade, the lesser the adverse event's threshold $(21,22)$. We therefore hypothesized that the more the specific CM types present, the more the DAs.

In this study, we hypothesized that (1) DAs are associated with CM, (2) specific types of CM can predict specific types of DAs, and (3) higher childhood trauma counts (CTCs) can predict more DAs.

\section{METHODS}

The set of data used for this study derives from a longitudinal project to scrutinize the psychological and biological mechanisms of MDD (hypothalamic-pituitary-adrenal axis function and magnetic resonance imaging study of trauma-related depression, registration no. ChiCTR1800014591).

One hundred seventy-one participants with MDD were enrolled from inpatient and outpatient departments of the Zhumadian Psychiatric Hospital (Henan, China), and 156 participants were recruited from the local area through flyers for a healthy control (HC) group. The enrolment procedure started in January 2013 and ended in December 2018. An eligibility criterion was set for the two groups, and two well-trained psychiatrists supervised the process.

The enrolment criteria set for the MDD group was as follows: (1) age 18-60 years, (2) diagnosed with MDD and medicationfree for not $<2$ weeks, (3) diagnosis of MDD confirmed by two well-trained psychiatrists using the Structured Clinical Interview for Diagnostic and Statistical Manual of Mental Disorders, Fourth Edition, (4) 24-item Hamilton Depression Rating Scale score $\left(\mathrm{HAMD}_{24}\right) \geq 20$ (23), and (5) consent form signed by the patient. The exclusion criteria set was as follows: (1) comorbid Axis I or II or a history of bipolar disorder; (2) history of head injury, neurological disorders, or other internal illnesses; (3) history of substance abuse or dependence except for tobacco dependence; and (4) having suicidal tendencies or ideation. As for the $\mathrm{HC}$ group, the inclusion criteria set was as follows: (1) age 1860 years, (2) $\mathrm{HAMD}_{24}$ score $<8$, and (3) signed consent form by the participant. The HC group's exclusion criteria were as follows: (1) history of any psychiatric disorders; (2) history of substance abuse or dependence except for tobacco dependence; and (3) history of head injury, neurological disorders, or other internal illnesses.

\section{Measures \\ Depression}

A 24-item $\mathrm{HAMD}_{24}$ was used to assess depression. It is a commonly used clinician-rated questionnaire (23). The scale was translated by the Shanghai Mental Health Center, and it summed up to have a good reliability and validity in the Chinese community. The scale consists of 24 items: 12 items were rated $0-4$, nine items were rated $0-2$, and three items were rated $0-3$. Hence, the total score ranges from 0 to 75 . A cutoff score of at least 20 signifies moderate depression (24).

\section{Anxiety}

A 14-item Hamilton Anxiety Rating Scale (HAMA 14 ) was used to assess anxiety among the participants. It is a clinician-rated questionnaire consisting of 14 items. Each item is rated on a range of 0 (absent) to 4 (severe). The total score ranges from 0 to 56 (25). The Chinese version of the HAMA 14 summed up to have a good reliability and validity in the Chinese community (26).

\section{Dysfunctional Attitudes}

The Dysfunctional Attitude Scale was used to assess cognitive vulnerabilities. The Chinese version of the Dysfunctional 
Attitude Scale-Form A (C-DAS-A) was used for the study. It is a self-reporting scale designed to evaluate DA's rectitude (27). This scale has good reliability and validity in Chinese MDD samples $(28,29)$. The Chinese version of the scale includes 40 items and encompasses eight subscales. The total score ranges from 40 to 280 , with higher the total score, the more DAs. The eight subscales are vulnerability, attraction and repulsion, perfectionism, compulsion, seeking applause, dependence, selfdetermination attitude, and cognition philosophy (28). More details about the C-DAS-A questionnaire and the nature of the several factors involved can be found in our other articles $(30,31)$.

\section{Childhood Maltreatment}

CM was assessed using the Childhood Trauma Questionnaire (CTQ). It is a retrospective assessment tool consisting of five factors for maltreatment, and it is evaluated through 28 items in the questionnaire. It accounts for maltreatment before the age of 16 years, and it is summed up to have good reliability and validity in the Chinese community. The five factors for CM assessed are EA, PA, SA, EN, and PN. Participants were identified as positive for $\mathrm{CM}$ if any one of these factors exceeded their cutoff score as mentioned: $\mathrm{EA}>12, \mathrm{PA}>9, \mathrm{SA}>7, \mathrm{EN}>14$, and $\mathrm{PN}>$ 9 (32-34). The CTC was defined as the sum of the total CTQ factors exceeding their respective cutoff scores. Its minimal score is therefore 0 , whereas the maximal score is 5 .

\section{Data Analytic Plan}

SPSS version 25.0 was used for the analytic procedure and a $p=0.05$ (two-tailed) for statistical significance. $\chi^{2}$ tests and independent $t$-tests were used to check for group differences for categorical variables and continuous variables, respectively, in the MDD and HC groups. To test our first hypothesis, that is, DAs are associated with CM; we used a $2 \times 2$ analysis of covariance (ANCOVA) of the diagnosis and CM on C-DAS-A total score with age, sex, and education as covariates; post-hoc analyses followed it. The same procedure was repeated with the eight C-DAS-A subscale scores as the dependent variable.

For our second hypothesis, a hierarchical regression analysis was used to estimate the different CM types' influence magnitude on C-DAS-A total score first. Then, the eight various C-DAS-A subscale scores replaced the C-DAS-A total score. The procedure was run in the two groups, MDD and HC groups, independently. Afterward, we assessed whether higher CTCs lead to more $\mathrm{DA}$, that is, our third hypothesis, by running a hierarchical regression analysis of CTC on C-DAS-A total score followed by its substitution with the eight different DAS factor scores. The process was run separately in the MDD and HC groups.

\section{RESULTS}

\section{Demographic/Clinical Information/Prevalence of CM, CM Types, and CTC}

Three hundred twenty-seven participants fulfilled the eligibility criteria, including $171 \mathrm{MDD}$ and $156 \mathrm{HC}$ participants. The mean age of the MDD group (35.06 years) was higher than the HC group (34.62 years). The average years of schooling in the MDD group (10.23 years) was lower than in the HC group (11.12 years). The male proportion was also lower in the MDD group (male 43.9\%) than that in the HC group (male 45.5\%).

Within the MDD group, the mean age at onset of depression was 31.74 years. The average number of episodes of depression was 2.03. There was no statistical significance in age and gender between MDD and HC groups $(p>0.05)$. Both $\mathrm{HC} / \mathrm{CM}^{+}$and $\mathrm{HC} / \mathrm{CM}^{-}$had more years of education compared to $\mathrm{MDD} / \mathrm{CM}^{+}$ and $\mathrm{MDD} / \mathrm{CM}^{-}$. The $\mathrm{MDD} / \mathrm{CM}^{+}$group had higher mean scores in $\mathrm{HAMD}_{24}, \mathrm{HAMA}_{14}$, C-DAS-A total, and CTQ total than the $\mathrm{MDD} / \mathrm{CM}^{-}$group, and they were all significant $(p<0.001)$. Clinical and demographic characteristics are shown in Table 1.

The prevalence of CM types and CTC is shown in Table 2. The prevalence of CM in our sample was $52.5 \%$, whereas $60.2 \%$ of the MDD group reported CM. PN (43.1\%) had the highest prevalence in the sample, in the MDD (49.7\%) and the HC (35.9\%) groups. SA (8.8\%) was the least prevalent form of $\mathrm{CM}$ among the MDD group, whereas EA (3.2\%) was the least common in the HC group.

Most participants (52.9\%) reported at least one type of CM from the sample, whereas $28.1 \%$ reported at least two types of $\mathrm{CM}, 7.3 \%$ reported at least three types of $\mathrm{CM}, 2.7 \%$ reported at least four types of CM, and $0.3 \%$ reported all types of CM.

A higher proportion of participants in the MDD group reported having experienced maltreatment in the past. Similarly, the proportion for the subtypes of CM was higher in the MDD group than that in the HC group. As for CTC, the HC group's proportion was higher than the MDD group for scores 0,1 , and 5 , whereas the reverse was observed with CTC scores 2,3 , and 4.

\section{Effect of Diagnosis and CM on C-DAS-A Total and Subscale Scores}

Table 3 shows the results of a $2 \times 2$ ANCOVA (factor 1: diagnosis and factor 2: CM) on C-DAS-A total and subscale scores with age, gender, and education as covariates. No significant two-way interaction effect of $\mathrm{CM}$ and diagnosis was found for C-DASA total score while controlling for covariates $(F=1.20, p=$ 0.275 , partial $\left.\eta^{2}=0.004\right)$. Therefore, an analysis of the main effects and the Bonferroni post-hoc test were performed for CM and diagnosis (35). The main effect of CM showed a statistically significant difference in unweighted adjusted marginal mean $(36,37)$ C-DAS-A total score for those who had CM (145.57) vs. those without CM (134.03) was 11.542 [95\% confidence interval (CI), 5.83-17.25; $p<0.001]$. As for the main effect of diagnosis, it showed a statistically significant difference in unweighted adjusted mean C-DAS-A total score for those of the MDD group (154.10) vs. those of the HC group (125.50). The difference was 28.60 (95\% CI, 23.04-34.16; $p<0.001$ ).

There was no statistically significant two-way interaction of $\mathrm{CM}$ and diagnosis while controlling for covariates, on CDAS-A subscale scores, except for C-DAS-A dependence. These statistically significant interactions were interpreted through analysis of main effects and Bonferroni post-hoc analyses of CM and diagnosis. The main effect of CM had statistically significant adjusted marginal means in the following C-DAS-A subscales: vulnerability (1.497, $p=0.009)$, attraction and repulsion $(2.717$, 
TABLE 1 | Demographics and clinical information of major depressive disorder (MDD) and healthy control (HC) groups.

\begin{tabular}{|c|c|c|c|c|c|c|c|}
\hline \multirow[t]{2}{*}{ Item } & \multicolumn{2}{|c|}{ MDD } & \multirow[t]{2}{*}{$p_{1}$} & \multicolumn{2}{|c|}{$\mathrm{HC}$} & \multirow[t]{2}{*}{$p_{2}$} & \multirow[t]{2}{*}{$P_{3}$} \\
\hline & $\begin{array}{c}\mathrm{CM}^{+} \\
(n=103) \\
\text { Mean } \pm \text { SD }\end{array}$ & $\begin{array}{c}\mathrm{CM}^{-} \\
(n=68) \\
\text { Mean } \pm \text { SD }\end{array}$ & & $\begin{array}{c}\mathrm{CM}^{+} \\
(n=69) \\
\text { Mean } \pm \text { SD }\end{array}$ & $\begin{array}{c}\mathrm{CM}^{-} \\
(n=87) \\
\text { Mean } \pm \text { SD }\end{array}$ & & \\
\hline Age (years) & $34.61 \pm 9.42$ & $35.74 \pm 10.08$ & 0.459 & $36.09 \pm 9.30$ & $33.45 \pm 8.96$ & 0.074 & 0.672 \\
\hline Gender (male/female) & $41 / 62$ & $34 / 34$ & - & $28 / 41$ & $43 / 44$ & - & 0.387 \\
\hline Education (years) & $9.55 \pm 3.29$ & $11.26 \pm 3.52$ & 0.001 & $10.26 \pm 3.37$ & $11.80 \pm 3.68$ & 0.008 & 0.024 \\
\hline $\mathrm{HAMD}_{24}$ & $32.01 \pm 7.67$ & $31.00 \pm 6.80$ & 0.379 & $1.79 \pm 1.89$ & $1.06 \pm 1.61$ & 0.011 & 0.000 \\
\hline $\mathrm{HAMA}_{14}$ & $18.54 \pm 6.32$ & $17.96 \pm 6.17$ & 0.551 & $1.55 \pm 2.14$ & $1.01 \pm 1.73$ & 0.084 & 0.000 \\
\hline C-DAS-A total & $159.11 \pm 25.50$ & $149.37 \pm 29.13$ & 0.022 & $133.13 \pm 22.83$ & $117.40 \pm 22.72$ & 0.000 & 0.000 \\
\hline CTQ & $48.12 \pm 9.20$ & $32.16 \pm 4.46$ & 0.000 & $44.94 \pm 8.81$ & $30.64 \pm 4.10$ & 0.000 & 0.000 \\
\hline Episodes & $1.98 \pm 1.18$ & $2.10 \pm 1.53$ & 0.556 & - & - & - & - \\
\hline Onset age (years) & $31.35 \pm 10.09$ & $32.36 \pm 10.30$ & 0.537 & - & - & - & - \\
\hline Current history & $5.20 \pm 11.00$ & $3.50 \pm 3.16$ & 0.217 & - & - & - & - \\
\hline Total history & $41.14 \pm 50.01$ & $42.32 \pm 53.13$ & 0.883 & - & - & - & - \\
\hline
\end{tabular}

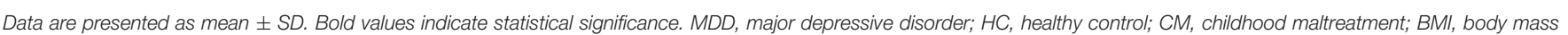

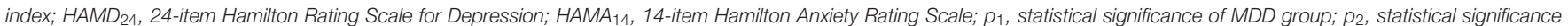
for HC group; $p_{3}$, statistical significance of MDD and HC groups.

TABLE 2 | Prevalence of childhood maltreatment and factors in the sample.

\begin{tabular}{|c|c|c|c|c|c|c|c|c|c|}
\hline & & \multicolumn{2}{|c|}{ MDD } & \multicolumn{2}{|c|}{$\mathrm{HC}$} & \multicolumn{2}{|c|}{ MDD+HC } & \multirow[t]{2}{*}{$\chi^{2}$} & \multirow[t]{2}{*}{$p$} \\
\hline & & $n$ & $\%$ & $\mathbf{n}$ & $\%$ & $\mathbf{n}$ & $\%$ & & \\
\hline \multicolumn{2}{|c|}{ Childhood maltreatment } & 103 & 60.2 & 69 & 44.2 & 172 & 52.6 & 8.380 & 0.004 \\
\hline \multicolumn{2}{|c|}{ Emotional abuse } & 16 & 9.4 & 5 & 3.2 & 21 & 6.4 & 5.137 & 0.023 \\
\hline \multicolumn{2}{|c|}{ Physical abuse } & 16 & 9.4 & 8 & 5.1 & 24 & 7.3 & 2.145 & 0.143 \\
\hline \multicolumn{2}{|c|}{ Sexual abuse } & 15 & 8.8 & 10 & 6.4 & 25 & 7.6 & 0.664 & 0.442 \\
\hline \multicolumn{2}{|c|}{ Emotional neglect } & 55 & 32.2 & 30 & 19.2 & 85 & 26.0 & 7.093 & 0.008 \\
\hline \multicolumn{2}{|c|}{ Physical neglect } & 85 & 49.7 & 56 & 35.9 & 141 & 43.1 & 6.344 & 0.012 \\
\hline \multirow[t]{6}{*}{ CTC } & 0 & 68 & 39.8 & 86 & 55.1 & 154 & 47.1 & 15.596 & 0.012 \\
\hline & 1 & 41 & 24.0 & 40 & 25.6 & 81 & 24.8 & & \\
\hline & 2 & 46 & 26.9 & 22 & 14.1 & 66 & 20.8 & & \\
\hline & 3 & 10 & 5.8 & 5 & 3.2 & 15 & 4.6 & & \\
\hline & 4 & 6 & 3.5 & 2 & 1.3 & 8 & 2.4 & & \\
\hline & 5 & 0 & 0.0 & 1 & 0.6 & 1 & 0.3 & & \\
\hline
\end{tabular}

Bold values indicate statistical significance. MDD, major depressive disorder; HC, healthy control; CTC, Childhood trauma count; $p$, statistical significance of $\chi^{2}$ test.

$p<0.001)$, perfectionism $(1.321, p=0.029)$, seeking applause (2.408, $p<0.001)$, and self-determination $(1.440, p=0.018)$. No statistically significant adjusted marginal mean scores were observed for the main effect of CM in C-DAS-A compulsion and cognition philosophy subscales $(p>0.131)$. As for the main effects of diagnosis group, there was a statistically significant adjusted marginal means in all of the eight subscale scores of C-DAS-A $(p<0.001)$.

As for C-DAS-A dependence, a statistically significant twoway interaction of $\mathrm{CM}$ and diagnosis was present while controlling for covariates $\left(F=4.55, p=0.034\right.$, partial $\eta^{2}=$ 0.014). Therefore, an analysis of simple main effects for CM and diagnosis was performed using a Bonferroni adjustment and being accepted at the $p<0.025$ level for both CM and diagnosis
(37-40). The effects of diagnosis for $\mathrm{CM}^{+}(F=18.635, p<0.001$, partial $\left.\eta^{2}=0.135\right)$ and $\mathrm{CM}^{-}\left(F=50.832, p<0.001\right.$, partial $\eta^{2}=$ $0.055)$ were both statistically significant. The effect of CM for the MDD group $\left(F=0.021, p=0.886\right.$, partial $\left.\eta^{2}=0.000\right)$ was not statistically significant, unlike that for the HC group $(F=9.588$, $p=0.002$, partial $\eta^{2}=0.029$ ).

\section{Hierarchical Regression Analysis of CM Types on C-DAS-A Total and Subscale Scores}

A hierarchical regression analysis was run at three levels to determine if CM types improved the prediction of C-DAS-A total and subscale scores in the MDD and HC groups. At level 1: age, 
TABLE 3 | Analysis of covariance (ANCOVA) of C-DAS-A total and subscale scores with age, gender, and education controlled.

\begin{tabular}{|c|c|c|c|c|c|c|c|c|c|c|c|c|}
\hline \multirow[t]{2}{*}{ C-DAS-A } & \multicolumn{2}{|c|}{ MDD } & \multicolumn{2}{|c|}{$\mathrm{HC}$} & \multirow[t]{2}{*}{$F_{1}$} & \multirow[t]{2}{*}{$p_{1}$} & \multicolumn{2}{|c|}{$\begin{array}{l}\text { Main effects } \\
\text { of diagnosis }\end{array}$} & \multicolumn{2}{|c|}{$\begin{array}{l}\text { Main effects } \\
\text { of } \mathrm{CM}\end{array}$} & \multicolumn{2}{|c|}{$\begin{array}{l}\text { Interaction effects } \\
\text { (CM and diagnosis) }\end{array}$} \\
\hline & $\begin{array}{c}\mathrm{CM}^{+} \\
(n=103) \\
\text { Mean } \pm \text { SD }\end{array}$ & $\begin{array}{c}\mathrm{CM}^{-} \\
(n=68) \\
\text { Mean } \pm \text { SD }\end{array}$ & $\begin{array}{c}\mathrm{CM}^{+} \\
(n=69) \\
\text { Mean } \pm \text { SD }\end{array}$ & $\begin{array}{c}\mathrm{CM}^{-} \\
(n=87) \\
\text { Mean } \pm \text { SD }\end{array}$ & & & $F_{2}$ & $p_{2}$ & $F_{3}$ & $p_{3}$ & $F_{4}$ & $p_{4}$ \\
\hline Total score & $\begin{array}{l}159.11 \\
\pm 25.5\end{array}$ & $\begin{array}{l}149.37 \\
\pm 29.13\end{array}$ & $\begin{array}{l}133.13 \\
\pm 22.83\end{array}$ & $\begin{array}{l}117.4 \\
\pm 22.72\end{array}$ & 24.71 & $<0.001$ & 102.44 & $<0.001$ & 15.83 & $<0.001$ & 1.20 & 0.275 \\
\hline Vulnerability & $\begin{array}{l}18.59 \\
\pm 4.67\end{array}$ & $\begin{array}{l}17.19 \\
\pm 4.34\end{array}$ & $\begin{array}{l}15.64 \\
\pm 4.81\end{array}$ & $\begin{array}{l}13.92 \\
\pm 3.81\end{array}$ & 9.83 & $<0.001$ & 38.97 & $<0.001$ & 8.54 & 0.004 & 0.10 & 0.754 \\
\hline Attraction and repulsion & $\begin{array}{l}19.18 \\
\pm 5.25\end{array}$ & $\begin{array}{l}16.90 \\
\pm 6.05\end{array}$ & $\begin{array}{l}14.65 \\
\pm 5.10\end{array}$ & $\begin{array}{l}11.30 \\
\pm 4.24\end{array}$ & 20.51 & $<0.001$ & 74.73 & $<0.001$ & 20.89 & $<0.001$ & 0.52 & 0.471 \\
\hline Perfectionism & $\begin{array}{l}18.91 \\
\pm 5.73\end{array}$ & $\begin{array}{l}18.38 \\
\pm 5.50\end{array}$ & $\begin{array}{l}16.10 \\
\pm 4.59\end{array}$ & $\begin{array}{l}13.83 \\
\pm 4.70\end{array}$ & 8.92 & $<0.001$ & 38.92 & $<0.001$ & 4.80 & 0.029 & 2.51 & 0.114 \\
\hline Compulsion & $\begin{array}{l}19.26 \\
\pm 4.75\end{array}$ & $\begin{array}{l}18.44 \\
\pm 4.21\end{array}$ & $\begin{array}{l}16.29 \\
\pm 4.12\end{array}$ & $\begin{array}{l}16.10 \\
\pm 3.59\end{array}$ & 9.71 & $<0.001$ & 29.17 & $<0.001$ & 0.05 & 0.828 & 0.68 & 0.410 \\
\hline Seeking applause & $\begin{array}{l}20.44 \\
\pm 5.44\end{array}$ & $\begin{array}{l}18.06 \\
\pm 4.95\end{array}$ & $\begin{array}{l}17.30 \\
\pm 4.51\end{array}$ & $\begin{array}{l}14.48 \\
\pm 4.55\end{array}$ & 12.57 & $<0.001$ & 36.03 & $<0.001$ & 18.01 & $<0.001$ & 0.41 & 0.522 \\
\hline Dependence & $\begin{array}{l}19.68 \\
\pm 4.65\end{array}$ & $\begin{array}{l}19.34 \\
\pm 4.80\end{array}$ & $\begin{array}{l}16.52 \\
\pm 3.96\end{array}$ & $\begin{array}{l}14.13 \\
\pm 4.48\end{array}$ & 14.95 & $<0.001$ & 66.28 & $<0.001$ & 5.22 & 0.023 & 4.55 & 0.034 \\
\hline Self-determination attitude & $\begin{array}{l}22.37 \\
\pm 5.88\end{array}$ & $\begin{array}{l}21.74 \\
\pm 5.21\end{array}$ & $\begin{array}{l}18.81 \\
\pm 5.03\end{array}$ & $\begin{array}{l}17.08 \\
\pm 4.60\end{array}$ & 10.76 & $<0.001$ & 52.94 & $<0.001$ & 5.67 & 0.018 & 0.53 & 0.467 \\
\hline Cognition philosophy & $\begin{array}{l}20.67 \\
\pm 5.32\end{array}$ & $\begin{array}{l}19.32 \\
\pm 5.21\end{array}$ & $\begin{array}{l}17.81 \\
\pm 4.06\end{array}$ & $\begin{array}{l}16.56 \\
\pm 5.15\end{array}$ & 7.94 & $<0.001$ & 22.73 & $<0.001$ & 2.29 & 0.131 & 0.34 & 0.853 \\
\hline
\end{tabular}

Data are presented as mean $\pm S D$. Bold values indicate statistical significance. HC, healthy control; CM, childhood maltreatment; C-DAS-A, Chinese version of Dysfunctional Attitude Scale-Form A; $F_{1}, F$ test value for corrected model; $p_{1}$, statistical significance of corrected model; $F_{2}$, F test value for main effects of $M D D ; p_{2}$, statistical significance for main effects of $M D D ; F_{3}$, $F$ test value for main effect of $C M$; $p_{3}$, statistical significance of main effect of $C M$; $F_{4}$, F test value for interaction effect between $C M$ and $M D D ; p_{4}$, statistical significance of interaction effect between $C M$ and $M D D$. 
gender, and education; level 2: $\mathrm{HAMA}_{14}$ and $\mathrm{HAMD}_{24}$; and level 3: EA, PA, SA, EN, and PN were included for the hierarchical regression analysis in the $\mathrm{HC}$ group, whereas in the MDD group, two supplementary items were added to level 2: duration of current episode and episode counts. As six participants had missing records of the $\mathrm{HAMA}_{14}$ data, they were removed from this investigation leading to a new sample size of 168 for the MDD group and 153 for the HC group.

The hierarchical regression analysis of CM types on C-DASA total and subscale scores within the MDD group is shown in Table 4. Within the MDD group, the CM types' addition to the model led to a statistically significant $\Delta R^{2}$ of $7.9 \%(p=0.015)$ with an EA standard coefficient of 0.249 in C-DAS-A total score. There was a statistically significant $\Delta R^{2}$ of $8.2 \%(p=0.015)$ in the C-DAS-A attraction and repulsion score and a statistically significant PN standard coefficient (0.276). In comparison, in the C-DAS-A self-determination, the EA (0.262) was statistically significant, with a $\Delta R^{2}$ of $6.9 \%(p=0.027)$.

Table 5 shows the hierarchical regression analysis of CM types on C-DAS-A total and subscale scores within the HC group. Only PN (0.216) was statistically significant, with a change in $R^{2}$ of $7.7 \%(p=0.033)$ observed in C-DAS-A seeking applause.

\section{Hierarchical Regression Analysis of CTC on C-DAS-A Total and Subscale Scores}

A hierarchical regression analysis was run to find CTC's predictability on C-DAS-A total and subscale scores in both the MDD $(n=168)$ and the HC $(n=153)$ groups. At level 1: age, gender, and education; level 2: $\mathrm{HAMA}_{14}$ and $\mathrm{HAMD}_{24}$; and level 3: CTC were included for the hierarchical regression analysis in the HC group, whereas in the MDD group, two supplementary items were added to level 2: duration of current episode and episode counts. The results are shown in Table 6. C-DAS-A total score had a significant predicted $\Delta R^{2}$ of $3.8 \%(p=0.010, \beta=$ 0.213 ) in the MDD group. Other C-DAS-A subscales that showed a significant $\Delta R^{2}$ were as follows: vulnerability $\left(\Delta R^{2}=2.5 \%\right.$, $p=0.042, \beta=0.171)$, attraction and repulsion $\left(\Delta R^{2}=5.4 \%\right.$, $p=0.002, \beta=0.253)$, and seeking applause $\left(\Delta R^{2}=3.4 \%, p\right.$ $=0.014, \beta=0.202)$. In the HC group, the C-DAS-A attraction and repulsion score $\left(\Delta R^{2}=2.7 \%, p=0.036, \beta=0.167\right)$ led to a statistically significant rise with the addition of CTC to the investigation.

\section{DISCUSSION}

Up to our knowledge, this study is among the few to investigate DAs as trait features of CM. The reported prevalence rate of CM among the depressed participants and HCs was $60.2 \%$ and $44.2 \%$, respectively. Our reported prevalence rate was much higher than a meta-analysis conducted in 2017 . However, the meta-analysis reported a comparatively lower prevalence rate of $45.6 \%$ among depressed participants (15). This discrepancy could be because our study was restricted to one region, and we had a smaller sample size. The disparity suggests that CM could be more frequent in some regions. The reported prevalence of specific $\mathrm{CM}$ types was comparatively lower, except for $\mathrm{PN}$, within the depressed participants (EA: $9.4 \%$ vs. $36.7 \%$; PA: $9.4 \%$ vs. $27.6 \%$; SA: $8.8 \%$ vs. $25.3 \%$; EN: $32.3 \%$ vs. $43.2 \%$; PN: $49.7 \%$ vs. $36.2 \%)$. Given our study's regional concept, China's rapid economic development meant parents have less time to interact with their children physically. As stated by the social development theorist Vygotsky, children do not develop in isolation; the lack of social interaction suffered by the children neglected by their caregivers constitutes a social impediment for their cognitive development.

Beck's cognitive theory of depression proposed that a negative self-schema is present before the onset of depression. Those cognitive distortions are results of adverse childhood experiences. They remain dormant until triggered by stressors $(16,41)$. By demonstrating cognitive differences between individuals who underwent CM and the depressed participants, this study provides essential support to Beck's cognitive theory of depression. We showed that CM predicts DAs in both participants with and without depression. Thereby, we understand that CM predicts some amount of DAs, which remain latent. We shared a similar tenet with a study about mood induction. They showed that DAs remain latent unless activated (42). We also shared similar results with a survey of 155 participants; they found a significant association between DAs and CM (43). However, only healthy participants with a comparatively lower mean age were involved in that study.

DAs are molded through adverse experiences starting from childhood. CM is among the risk factors for cognitive vulnerabilities (44). Maltreated children make inferences in trying to understand maltreatment events. With the repetition of those events, the children can develop DAs by negative cognitive structuring and faulty information processing. Ultimately, depression is the result when those are triggered $(21,44,45)$. Studies have found that EA and EN had a strong association with DAs $(46,47)$. They are also predictive of future depressive episodes (48-50), mediated by DAs (43). Our study is on similar lines. We found that individuals with EA were likely to develop more DAs of self-determination attitude type and overall DAs among the depressed participants. It is possible that those two types of DAs might influence the pathway from EA to depression. Individuals with DAs of self-determination attitude type are those with the thought of casting one's values in comparison with others (e.g., "If I do not do as well as other people, it means I am an inferior human being") (28). A group of researchers shared similar findings; they discussed the relationship between EA and depression mediated by DAs (19).

Failure to cater to a child's basic needs by caregivers, either deliberately or unknowingly, defines $\mathrm{CN}$. The child is deprived of basic needs, safety, supervision, medical care, physical requirements, and emotional support (1). $\mathrm{CN}$ includes $\mathrm{PN}$ and EN. It is the most prominent form of CM worldwide, and its high prevalence can be seen in our study. Approximately one in six children will experience CN (51). Studies have shown that $\mathrm{CN}$ impedes the development of the corpus callosum areas (52), and those alterations correlate with depression (53-55). An interesting result from our research indicated that $\mathrm{PN}$ is bound to more DAs: attraction and repulsion-type DA in the depressed and seeking applause-type DA in the non-depressed. However, a study of 155 healthy participants with a mean age of 18.8 
TABLE 4 | Hierarchical regression analysis of childhood maltreatment types on C-DAS-A total and subscale scores in the MDD group $(n=168)$.

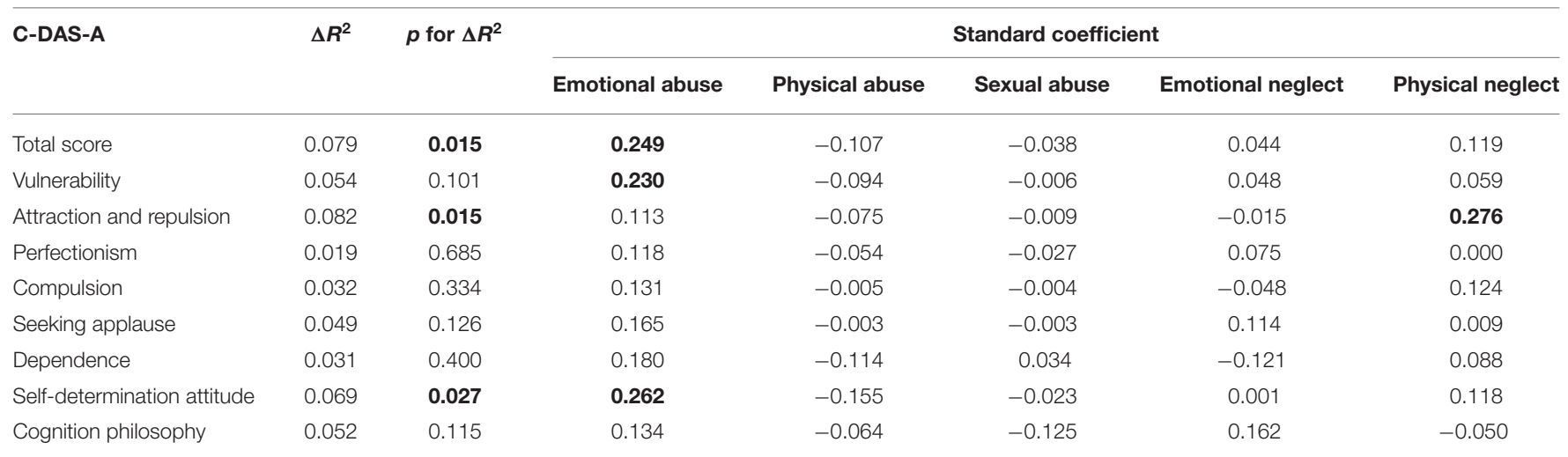

Bold values indicate statistical significance. The $\Delta R^{2}$ indicates the changes $R^{2}$ of the model from level 2 to level 3 . The three hierarchies of the regression model were as follows: level 1: age, sex, education; level 2: HAMA $A_{14}, H A M D_{24}$, duration of current episodes, episode counts; level 3: childhood maltreatment types. C-DAS-A, Chinese version of Dysfunctional Attitude Scale-Form A.

TABLE 5 | Hierarchical regression analysis of childhood maltreatment types on C-DAS-A total and subscale scores in the HC group; $(n=153)$.

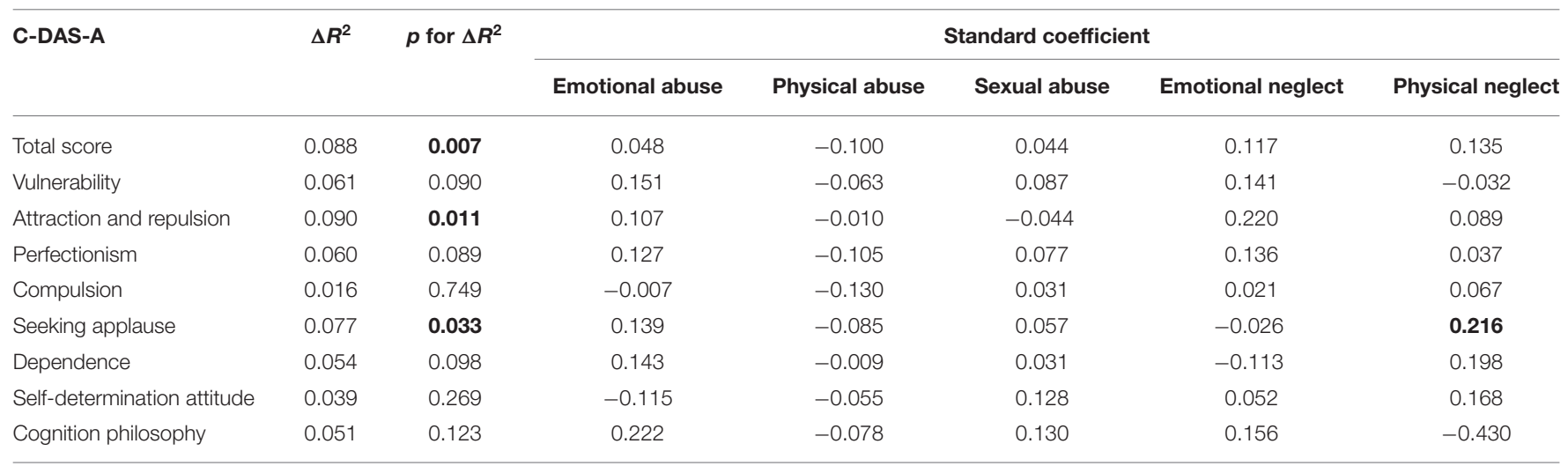

Bold values indicate statistical significance. The $\Delta R^{2}$ indicates the changes $R^{2}$ of the model from level 2 to level 3 . The three hierarchies of the regression model were as follows: level 1: age, sex, education; level 2: HAMA $14, H A M D_{24}$; level 3: childhood maltreatment types. C-DAS-A, Chinese version of Dysfunctional Attitude Scale-Form A; HC, healthy control.

TABLE 6 | Hierarchical regression analysis of childhood trauma count on C-DAS-A total and subscale scores in the MDD $(n=168)$ and the HC ( $n=153)$ groups.

\begin{tabular}{|c|c|c|c|c|c|c|}
\hline \multirow[t]{2}{*}{ C-DAS-A } & \multicolumn{3}{|c|}{$\begin{array}{c}\text { MDD } \\
(n=168)\end{array}$} & \multicolumn{3}{|c|}{$\begin{array}{l}\text { HC group } \\
(n=153)\end{array}$} \\
\hline & $\Delta R^{2}$ & $p$ for $\Delta R^{2}$ & $\begin{array}{c}\text { Standard coefficient } \\
\text { for CTC }\end{array}$ & $\Delta R^{2}$ & $p$ for $\Delta R^{2}$ & $\begin{array}{c}\text { Standard coefficient } \\
\text { for CTC }\end{array}$ \\
\hline Total score & 0.038 & 0.010 & 0.213 & 0.011 & 0.156 & 0.108 \\
\hline Vulnerability & 0.025 & 0.042 & 0.171 & 0.002 & 0.555 & 0.048 \\
\hline Perfectionism & 0.010 & 0.206 & 0.107 & 0.002 & 0.629 & 0.039 \\
\hline Compulsion & 0.012 & 0.138 & 0.121 & 0.000 & 0.829 & -0.017 \\
\hline Seeking applause & 0.034 & 0.014 & 0.202 & 0.014 & 0.137 & 0.121 \\
\hline Dependence & 0.001 & 0.681 & 0.035 & 0.007 & 0.280 & 0.084 \\
\hline Self-determination attitude & 0.019 & 0.064 & 0.150 & 0.008 & 0.255 & 0.090 \\
\hline Cognition philosophy & 0.005 & 0.363 & 0.076 & 0.000 & 0.874 & 0.012 \\
\hline
\end{tabular}

Bold values indicate statistical significance. The three hierarchies of the regression model in the MDD group were as follows: level 1: age, sex, education; level 2: HAMA 14 , HAMD 24 , duration of current episode, episode counts; level 3: childhood maltreatment types. The three hierarchies of the regression model in the HC group were as follows: level 1: age, sex, education; level 2: HAMA $14, H A M D_{24}$; level 3: childhood trauma counts. The $\Delta R^{2}$ indicates the changes $R^{2}$ of the model from level 2 to level 3. C-DAS- $A$, Chinese version of Dysfunctional Attitude Scale-Form A; HC, healthy control; CTC, childhood trauma count. 
years found that physical maltreatment was not related to DAs. In their research, physical maltreatment englobed PA and PN. Their selection of only healthy participants makes it difficult for us to weigh up our depression group results. Nevertheless, we could compare the findings of our control group. The reason behind this discrepancy could be the merging of PA and PN into one category (43), as PA was reported not to be associated with DAs (19). CN was found to be predictive of DAs among depressed participants in a study (20), partly supporting our findings for PN.

Exposure to one form of trauma in childhood potentially elevates the risk of experiencing several forms of trauma over time. Polyvictimization is the term used to describe individuals who experienced potentially traumatic events such as the known components of CM, bullying, and witnessing adverse events such as parent substance abuse, domestic violence, and others $(56,57)$. It is a robust predictor of short- and long-term mental health problems not limited to depression $(14,58)$. Like a few, we also used the CTQ to assess an aspect of polyvictimization. They found a "dose-dependent" relationship between collective CM types and the odds of being diagnosed with depression $(59,60)$. Our study added a new scope in polyvictimization; we further assessed which type of DA is more likely in depressed and non-depressed individuals. With increased CTCs, DAs of vulnerability type, attraction and repulsion type, and seeking applause type and overall DAs were predicted in depressed patients. In those without depression, increased CTCs predicted DAs of attraction and repulsion type. Our results were in line with the titration model of the cognitive vulnerability. It states that a lesser threshold of adverse events is required when more negative cognitive styles are present to onset depression $(21,22)$.

\section{LIMITATIONS}

A couple of limitations concerning this study should be noted. First, the nature of our research is a hurdle to make reverse causality inferences. We could not show the direct causality of DAs associated with CM and account for time exposed to $\mathrm{CM}$. Second, the retrospective assessment of CM using the CTQ is subject to recall biases. Also, some forms of CM such as SA might be underreported in fear of shame and social detriment. Third, polyvictimization is best assessed using the Juvenile Victimization Questionnaire (JVC) (57). As most of the JVC components overlapped with the CTQ, we adopted the latter for our study's purposes. Two researchers endorsed the same method $(59,60)$. They assessed polyvictimization by grading the severity of the individual CTQ factors. We used a dichotomous format for each factor of the CTQ; either presence or absence could be the outcome, ignoring the severity of the CTQ factors.

\section{CONCLUSIONS}

Our group of researchers brought up the novel idea to examine the type of DAs predicted by CM types, and we are the only to explore the types of DA predicted by higher CTCs. In summary, our study provided new insights into the clinical field. Specific types of DAs might influence the relationship between MDD and CM. Furthermore, we also concluded that the higher the CTCs, the more DA types in participants with and without depression. Screening and prevention of CM by related authorities, caregivers, medical professionals, and parents are imperative to break the chain. EA or PN typically deserves better attention; they may be potential markers to screen for depression. Research has shown that psychotherapy alone or in combination with antidepressants is best suited in depressed patients who underwent CM (61). Cognitive-behavioral therapy (CBT), personalized trauma-focused CBT, and child-parent psychotherapy are recommended. The forms of DA associated with depression found in our study should to be focused on to address ongoing or future depressive episodes.

\section{DATA AVAILABILITY STATEMENT}

The raw data supporting the conclusions of this article will be made available by the authors, without undue reservation.

\section{ETHICS STATEMENT}

The studies involving human participants were reviewed and approved by the Ethics Committee of the Second Xiangya Hospital of Central South University and Ethic Committee of the Zhumadian Psychiatric Hospital. The patients/participants provided their written informed consent to participate in this study.

\section{AUTHOR CONTRIBUTIONS}

LL, YZ, and BL co-designed the topic. BL, JS, MW, XL, QD, LZ, JL, YJ, PW, HG, FZ, and YZ are responsible for participant recruitment and data collection. $\mathrm{RJ}$ and $\mathrm{BL}$ co-conducted the statistical analyses. RJ wrote the initial draft of the manuscript. BL contributed important revisions to the manuscript. All authors contributed to the article and approved the submitted version.

\section{FUNDING}

This study was supported by the National Science and Technologic Program of China (2015BAI13B02), the Defense Innovative Special Region Program (17-163-17-XZ-004-005-01), the National Natural Science Foundation of China (81171286, 91232714 , and 81601180 ). The funding sources had no role in the study design, data collection and analysis, interpretation of the data, preparation and approval of the manuscript, and decision to submit the manuscript for publication.

\section{ACKNOWLEDGMENTS}

We thank all participants for participating in this study. 


\section{REFERENCES}

1. World Health Organization. Preventing Child Maltreatment: A Guide to Taking Action and Generating Evidence. Geneva: World Health Organization (2012).

2. Hillis S, Mercy J, Amobi A, Kress H. Global prevalence of past-year violence against children: a systematic review and minimum estimates. Pediatrics. (2016) 137:e20154079. doi: 10.1542/peds.2015-4079

3. Bradshaw J, Hooper C-A. Child maltreatment. In: Bradshaw J. editor. The Well-Being of Children in the UK. Bristol: The Policy Press (2011). p. 191-211.

4. Chapman DP, Whitfield CL, Felitti VJ, Dube SR, Edwards VJ, Anda RF. Adverse childhood experiences and the risk of depressive disorders in adulthood. J Affect Disord. (2004) 82:217-25. doi: 10.1016/j.jad.2003.12.013

5. Abbasi MA, Saeidi M, Khademi G, Hoseini BL, Moghadam ZE. Child maltreatment in the worldwide: a review article. Int J Pediatr. (2015) 3:353-65. doi: 10.22038/IJP.2015.3753

6. Cicchetti D, Toth SL. Child maltreatment. Annu Rev Clin Psychol. (2005) 1:409-38. doi: 10.1146/annurev.clinpsy.1.102803.144029

7. Herringa RJ, Birn RM, Ruttle PL, Burghy CA, Stodola DE, Davidson RJ, et al. Childhood maltreatment is associated with altered fear circuitry and increased internalizing symptoms by late adolescence. Proc Natl Acad Sci U S A. (2013) 110:19119-24. doi: 10.1073/pnas.1310766110

8. Vos T, Lim SS, Abbafati C, Abbas KM, Abbasi M, Abbasifard M, et al. Global burden of 369 diseases and injuries in 204 countries and territories, 19902019: a systematic analysis for the Global Burden of Disease Study 2019. Lancet. (2020) 396:1204-22. doi: 10.1016/S0140-6736(20)30925-9

9. Klumparendt A, Nelson J, Barenbrügge J, Ehring T. Associations between childhood maltreatment and adult depression: a mediation analysis. BMC Psychiatry. (2019) 19:36. doi: 10.1186/s12888-019-2016-8

10. Nanni V, Uher R, Danese A. Childhood maltreatment predicts unfavorable course of illness and treatment outcome in depression: a meta-analysis. Am J Psychiatry. (2012) 169:141-51. doi: 10.1176/appi.ajp.2011.11020335

11. Li M, D’Arcy C, Meng X. Maltreatment in childhood substantially increases the risk of adult depression and anxiety in prospective cohort studies: systematic review, meta-analysis, and proportional attributable fractions. Psychol Med. (2016) 46:717-30. doi: 10.1017/S0033291715002743

12. Comijs HC, Van Exel E, Van Der Mast RC, Paauw A, Oude Voshaar R, Stek ML. Childhood abuse in late-life depression. J Affect Disord. (2013) 147:241-6. doi: 10.1016/j.jad.2012.11.010

13. Bernet CZ, Stein MB. Relationship of childhood maltreatment to the onset and course of major depression in adulthood. Depress Anxiety. (1999) 9:169-74.

14. Norman RE, Byambaa $M$, De R, Butchart A, Scott J, Vos T. The long-term health consequences of child physical abuse, emotional abuse, and neglect: a systematic review and meta-analysis. PLoS Med. (2012) 9:e1001349. doi: 10.1371/journal.pmed.1001349

15. Nelson J, Klumparendt A, Doebler P, Ehring T. Childhood maltreatment and characteristics of adult depression: meta-analysis. Br J Psychiatry. (2017) 210:96-104. doi: 10.1192/bjp.bp.115.180752

16. Beck AT, Rush AJ, Shaw BF EG. Cogn Ther Depress. New York, NY: Guildf Press (1979).

17. Ezawa ID, Forand NR, Strunk DR. An examination of dysfunctional attitudes and extreme response styles as predictors of relapse in guided internetbased cognitive behavioral therapy for depression. J Clin Psychol. (2020) 76:1047-59. doi: 10.1002/jclp.22955

18. Pedrelli P, Feldman GC, Vorono S, Fava M, Petersen T. Dysfunctional attitudes and perceived stress predict depressive symptoms severity following antidepressant treatment in patients with chronic depression. Psychiatry Res. (2008) 161:302-8. doi: 10.1016/j.psychres.2007.08.004

19. Akbaba Turkoglu S, Essizoglu A, Kosger F, Aksaray G. Relationship between dysfunctional attitudes and childhood traumas in women with depression. Int J Soc Psychiatry. (2015) 61:796-801. doi: 10.1177/0020764015585328

20. Peng H, Long Y, Li J, Guo Y, Wu H, Yang YL, et al. Hypothalamicpituitary-adrenal axis functioning and dysfunctional attitude in depressed patients with and without childhood neglect. BMC Psychiatry. (2014) 14:17. doi: 10.1186/1471-244X-14-45

21. Abramson LY, Metalsky GI, Alloy LB. Hopelessness depression: a theory-based subtype of depression. Psychol Rev. (1989) 96:358-72. doi: 10.1037/0033-295X.96.2.358
22. Abramson LY. Cognitive/personality subtypes of depression: theories in search of disorders. Cognit Ther Res. (1997) 21:24765. doi: 10.1023/A:1021870315058

23. Hamilton M. A rating scale for depression. J Neurol Neurosurg Psychiatry. (1960) 23:56-62. doi: 10.1136/jnnp.23.1.56

24. Tang Y, Zhang M. HAMD. Shanghai Ment Heal Cent. (1984) 4:9-12.

25. Hamilton M. The assessment of anxiety states by rating. Br J Med Psychol. (1959) 32:50-5. doi: 10.1111/j.2044-8341.1959.tb00467.x

26. Wang C, Chu Y, Zhang Y, Zhang N, Zhang J, Yang H. Study on factor structure of hamilton rating scale for anxiety. J Clin Psychiatry. (2011) 21:299-301.

27. Weissman AN, Beck AT. Development and validation of the dysfunctional attitude scale a preliminary investigation. In: The 62nd Annual Meeting of the American Educational Research Association; 1978 March 27-31 (Toronto, ON) (1978).

28. Chen Y, Xu J, Yan S, Xian Y, Li Y, Chang X, et al. A study of the dysfunction attitude scale. China Chinese Ment Heal. (1998) 12:265-8.

29. Wong DFK, Kin SC, Lau Y. The reliability and validity of the Chinese version of the dysfunctional attitudes scale form a (DAS-A) in a community sample. Int J Psychiatry Med. (2008) 38:141-52. doi: 10.2190/PM.38.2.b

30. Liu B, Sun J, Qin X, Wang M, Lu X, Dong Q, et al. State-dependent and traitlike characteristics of dysfunctional attitudes in patients with major depressive disorder. Front Psychiatry. (2020) 11:1. doi: 10.3389/fpsyt.2020.00645

31. Qin X, Sun J, Wang M, Lu X, Dong Q, Zhang L, et al. Gender differences in dysfunctional attitudes in major depressive disorder. Front Psychiatry. (2020) 11:86. doi: 10.3389/fpsyt.2020.00086

32. Bernstein DP, Fink L, Handelsman L, Foote J, Lovejoy M, Wenzel K, et al. Initial reliability and validity of a new retrospective measure of child abuse and neglect. Am J Psychiatry. (1994) 151:1132-6. doi: 10.1176/ajp.151.8.1132

33. Bernstein DP, Stein JA, Newcomb MD, Walker E, Pogge D, Ahluvalia $\mathrm{T}$, et al. Development and validation of a brief screening version of the Childhood Trauma Questionnaire. Child Abus Negl. (2003) 27:16990. doi: 10.1016/S0145-2134(02)00541-0

34. Fu WQ, Yao S-Q. Initial reliability and validity of Childhood Trauma Questionnaire (CTQ-SF) applied in Chinese college students. Chin J Clin Psychol. (2005) 13:40-2. doi: 10.16128/j.cnki.1005-3611.2005.01.012

35. Howell DC. Statistical Methods for Psychology. 7th ed. Belmont, CA: Wadsworth, Cengage Learning (2010).

36. Fox J. Applied regression analysis and generalized linear models. 2nd ed. Thousand Oaks, CA: SAGE Publications (2008).

37. Maxwell SE, Delaney HD. Designing Experiments and Analyzing Data: A Model Comparison Perspective. 2nd ed. New York, NY: Psychology Press (2004).

38. Kinnear PR, Gray CD. PASW 17 Statistics Made Simple. New York, NY: Psychology Press (2010).

39. Keppel G, Wickens TD. Design and Analysis: A Researcher's Handbook. 4th ed. Upper Saddle River, NJ: Prentice Hall (2004).

40. Jaccard J. Interaction Effects in Factorial Analysis of Variance. Thousand Oaks, CA: SAGE Publications, Inc. (1998).

41. Beck AT. The evolution of the cognitive model of depression and its neurobiological correlates. Am J Psychiatry. (2008) 165:969-77. doi: 10.1176/appi.ajp.2008.08050721

42. Miranda J, Gross JJ, Persons JB, Hahn J. Mood matters: negative mood induction activates dysfunctional attitudes in women vulnerable to depression. Cognit Ther Res. (1998) 22:363-76. doi: 10.1023/A:1018709212986

43. Wells TT, Vanderlind WM, Selby EA, Beevers CG. Childhood abuse and vulnerability to depression: cognitive scars in otherwise healthy young adults. Cogn Emot. (2014) 28:821-33. doi: 10.1080/02699931.2013.864258

44. Rose DT, Abramson LY. Developmental predictors of depressive cognitive style: research and theory. Rochester Symp Dev Psychopathol. (1992) 4:323-49.

45. Alloy LB, Abramson LY, Smith JM, Gibb BE, Neeren AM. Role of parenting and maltreatment histories in unipolar and bipolar mood disorders: mediation by cognitive vulnerability to depression. Clin Child Fam Psychol Rev. (2006) 9:23-64. doi: 10.1007/s10567-006-0002-4

46. Gibb BE, Abramson LY, Alloy LB. Emotional maltreatment from parents, verbal peer victimization, and cognitive vulnerability to depression. Cognit Ther Res. (2004) 28:1-21. doi: 10.1023/B:COTR.0000016927.18027.c2

47. Gibb BE. Childhood maltreatment and negative cognitive styles. Clin Psychol Rev. (2002) 22:223-46. doi: 10.1016/S0272-7358(01)00088-5 
48. Maric N, Andric S, Mihaljevic M, Mirjanic T, Pavlovic Z. Sub-types of childhood trauma predicts depressive and anxiety symptoms in the general population. Eur Psychiatry. (2016) 33:S516. doi: 10.1016/j.eurpsy.2016.01.1908

49. Gibb BE, Alloy LB, Abramson LY, Rose DT, Whitehouse WG, Donovan $\mathrm{P}$, et al. History of childhood maltreatment, negative cognitive styles, and episodes of depression in adulthood. Cognit Ther Res. (2001) 25:42546. doi: 10.1023/A:1005586519986

50. Martins CMS, Von Werne Baes C, De Carvalho Tofoli SM, Juruena MF. Emotional abuse in childhood is a differential factor for the development of depression in adults. J Nerv Ment Dis. (2014) 202:77482. doi: 10.1097/NMD.0000000000000202

51. Stoltenborgh M, Bakermans-Kranenburg MJ, Van Ijzendoorn MH. The neglect of child neglect: a meta-analytic review of the prevalence of neglect. Soc Psychiatry Psychiatr Epidemiol. (2013) 48:345-55. doi: 10.1007/s00127-012-0549-y

52. Teicher MH, Dumont NL, Ito Y, Vaituzis C, Giedd JN, Andersen SL. Childhood neglect is associated with reduced corpus callosum area. Biol Psychiatry. (2004) 56:80-5. doi: 10.1016/j.biopsych.2004.03.016

53. Guo W, Liu F, Xue Z, Gao K, Wu R, Ma C, Liu Z, et al. Altered white matter integrity in young adults with first-episode, treatmentnaive, and treatment-responsive depression. Neurosci Lett. (2012) 522:13944. doi: 10.1016/j.neulet.2012.06.027

54. Kemp A, Macmaster FP, Jaworska N, Yang XR, Pradhan S, Mahnke D, et al. Age of onset and corpus callosal morphology in major depression. J Affect Disord. (2013) 150:703-6. doi: 10.1016/j.jad.2013.05.009

55. Peng H, Ning Y, Zhang Y, Yang H, Zhang L, He Z, et al. White-matter density abnormalities in depressive patients with and without childhood neglect: a voxel-based morphometry (VBM) analysis. Neurosci Lett. (2013) 550:23-8. doi: 10.1016/j.neulet.2013.06.048

56. Finkelhor D, Ormrod RK, Turner HA. Poly-victimization: a neglected component in child victimization. Child Abus Negl. (2007) 31:7-26. doi: 10.1016/j.chiabu.2006.06.008

57. Finkelhor D, Ormrod RK, Turner HA, Hamby SL. Measuring polyvictimization using the Juvenile Victimization Questionnaire. Child Abus Negl. (2005) 29:1297-312. doi: 10.1016/j.chiabu.2005.06.005
58. Negele A, Kaufhold J, Kallenbach L, Leuzinger-Bohleber M. Childhood trauma and its relation to chronic depression in adulthood. Depress Res Treat. (2015) 2015:650804. doi: 10.1155/2015/650804

59. Novelo M, von Gunten A, Gomes Jardim GB, Spanemberg L, Argimon II de L, Nogueira EL. Effects of childhood multiple maltreatment experiences on depression of socioeconomic disadvantaged elderly in Brazil. Child Abuse Negl. (2018) 79:350-7. doi: 10.1016/j.chiabu.2018.02.013

60. Dovran A, Winje D, Arefjord K, Tobiassen S, Stokke K, Skogen JC, Øverland S. Associations between adverse childhood experiences and adversities later in life. Survey data from a high-risk Norwegian sample. Child Abuse Negl. (2019) 98:104234. doi: 10.1016/j.chiabu.2019.104234

61. Nemeroff CB, Heim CM, Thase ME, Klein DN, Rush AJ, Schatzberg AF, et al. Differential responses to psychotherapy versus pharmacotherapy in patients with chronic forms of major depression and childhood trauma. Proc Natl Acad Sci U S A. (2003) 100:14293-6. doi: 10.1073/pnas.23361 26100

Conflict of Interest: The authors declare that the research was conducted in the absence of any commercial or financial relationships that could be construed as a potential conflict of interest.

Publisher's Note: All claims expressed in this article are solely those of the authors and do not necessarily represent those of their affiliated organizations, or those of the publisher, the editors and the reviewers. Any product that may be evaluated in this article, or claim that may be made by its manufacturer, is not guaranteed or endorsed by the publisher.

Copyright (C) 2021 Jugessur, Zhang, Qin, Wang, Lu, Sun, Dong, Zhang, Liu, Ju, Liao, Wan, Guo, Zhao, Liu and Li. This is an open-access article distributed under the terms of the Creative Commons Attribution License (CC BY). The use, distribution or reproduction in other forums is permitted, provided the original author(s) and the copyright owner(s) are credited and that the original publication in this journal is cited, in accordance with accepted academic practice. No use, distribution or reproduction is permitted which does not comply with these terms. 